\title{
IN VITRO INDUCTION OF ENAMEL SUBSURFACE DEMINERALIZATION FOR EVALUATION OF DIAGNOSTIC IMAGING METHODS
}

\author{
Rívea Inês FERREIRA ${ }^{1}$, Francisco HAITER-NETO ${ }^{2}$, Cínthia Pereira Machado TABCHOURY ${ }^{3}$, Frab Norberto BÓSCOLO ${ }^{4}$
}

\author{
1- DDS, MS, PhD, Associate Professor, Department of Orthodontics, University of Sao Paulo City, Brazil. \\ 2- DDS, MS, PhD, Professor, Department of Oral Diagnosis, Piracicaba Dental School, State University of Campinas, Brazil. \\ 3- Pharm.D, MS, PhD, Associate Professor, Department of Physiological Sciences, Piracicaba Dental School, State University of Campinas, \\ Brazil. \\ 4- DDS, PhD, Professor and Chairman, Department of Oral Diagnosis, Piracicaba Dental School, State University of Campinas, Brazil.
}

Corresponding address: Rívea Inês Ferreira - Universidade Cidade de São Paulo - Rua Cesário Galeno, 448 - Bloco B - Pós-Graduação Tatuapé, São Paulo, Brasil - 03071-000 - Phone: 5519 32512334. e-mail: riveaines@directnet.com.br

Received: July 24, 2006 - Modification: February 09, 2007 - Accepted: July 17, 2007

\begin{abstract}
T maging methods. Fifty sound teeth had their crowns coated with acid-resistant varnish, leaving a $7 \mathrm{~mm}^{2}$ circular window of exposed enamel in one of the proximal surfaces. The specimens were assigned to 5 groups (4 experimental and the control) and were kept immersed in a buffer solution at $\mathrm{pH} 4.8,50 \%$ saturated in relation to enamel, for 60, 75, 90 and 120 days, or were not exposed to the solution. Digital radiographs were taken, prior to and after each immersion period, and interpreted by a radiologist. For validation, the enamel was submitted to microhardness profiling. In addition, the solutions were analyzed for phosphorus $\left(\mathrm{P}_{\mathrm{i}}\right)$ and calcium $(\mathrm{Ca})$ concentrations. Microhardness data were evaluated using two-way ANOVA $(\mathrm{p}<0.05)$ and Tukey's test. $P_{i}$ and Ca concentrations were compared using one-way ANOVA $(\alpha=0.05)$. The performance of radiography was assessed by ROC analysis. The microhardness values for the control group ranged from 405 to 432 KHN. Of the 4 experimental groups, the 60-day group demonstrated the highest values (179-379 KHN) and the 120-day group, the lowest values (103-277 $\mathrm{KHN})$. The lowest total concentrations of $\mathrm{P}_{\mathrm{i}}$ and $\mathrm{Ca}(1.74 \mathrm{mM}$ and $2.63 \mathrm{mM}$, respectively) were found in the solutions of the 60 day group, indicating the lowest rate of mineral loss, however, there was no significant difference among the other experimental groups. The performance for detecting images consistent with caries lesions was high $\left(\mathrm{A}_{\mathrm{z}}=0.89\right)$. Therefore, this in vitro model of inducing demineralization may be considered suitable for research intended to evaluate imaging methods for the diagnosis of proximal caries lesions.
\end{abstract}

Uniterms: Dental caries; Demineralization; Dental enamel; Diagnosis.

\section{INTRODUCTION}

Dental caries is a dynamic process resulting from biochemical and ultrastructural alterations, which culminate in characteristic signs and symptoms ${ }^{2,16,19}$. Several in vitro and in situ models using cariogenic bacteria and acidified media have been developed to induce enamel demineralization, with histological features similar to those observed in natural caries lesions $\mathbf{s}^{4,5,14}$. Although these models do not reproduce the complexity of the events occurring in the mouth, they are very useful for caries studies, especially those focusing on caries lesions progression.

The major goal in the diagnosis of dental caries should be the early detection of signs. Widely used in dental settings, radiography is a satisfactory method to detect and follow up proximal caries lesions ${ }^{20}$. However, one disadvantage of the models designed to induce demineralization is that most use enamel blocks and not the entire tooth. Consequently, monitoring the artificial lesions by radiographic examination becomes quite impracticable. Thus, the aim of the present study was to evaluate the applicability of an experimental model for inducing subsurface enamel demineralization in human permanent teeth.

\section{MATERIALAND METHODS}

This study is in agreement with the Resolution 196/96 from the National Health Council/Health Department (Brazil) and was approved by the Ethics in Human Research Committee of the Dental School of Piracicaba, State University of Campinas (UNICAMP), Sao Paulo, Brazil. 


\section{Sampling}

Fifty unerupted or partially erupted human sound third molars with at least two thirds of the roots formed were selected. After extraction, the teeth were washed in saline to remove blood residues, then polished with pumice and thoroughly cleaned with distilled water.

\section{Tooth preparation}

The root portion of each tooth was embedded in a rectangular block of self-curing acrylic resin. The crowns were coated with a fast-drying acid-resistant red nail polish (Colorama Express ${ }^{\circledR}$, Colorama/CEIL, Sao Paulo, Brazil), leaving only a $7 \mathrm{~mm}^{2}$ circular window of exposed enamel in one of the proximal surfaces. Blocks were numbered and randomly assigned to five groups (four experimental and one control) of 10 specimens each.

\section{Demineralization regimen}

Based on previous investigations ${ }^{4,18}$, a buffer solution $50 \%$ saturated in relation to dental enamel was developed and tested by pilot studies for inducing enamel subsurface demineralization. This demineralizing solution ( $\mathrm{pH} 4.8$ ) contained $0.05 \mathrm{M}$ acetate buffer, $1.12 \mathrm{mM}$ calcium, $0.77 \mathrm{mM}$ phosphate, 0.03 ppm fluoride and thymol. Phosphorus $\left(\mathrm{P}_{\mathrm{i}}\right)$ and calcium $(\mathrm{Ca})$ concentrations were determined in samples of the demineralizing solution prior to use.

The ratio recommended for use is $2 \mathrm{~mL}$ of demineralizing solution to $1 \mathrm{~mm}^{2}$ of exposed enamel. Since the exposed enamel area was approximately $7 \mathrm{~mm}^{2}$, the specimens of the experimental groups were kept individually immersed in 14 $\mathrm{mL}$ of the demineralizing solution and incubated at $37^{\circ} \mathrm{C}$ for $60,75,90$ or 120 days. The experimental groups were designated according to the time interval of the demineralization period, i.e., 60-day group, 75-day group, 90-day group and 120-day group. Control specimens were individually kept in plastic recipients consisting of a pellet of cotton moistened with distilled and deionized water, at $37^{\circ} \mathrm{C}$ for 120 days. The exposed enamel area was thus maintained in humid condition without direct contact with water, avoiding ionic exchanges.

The pilot studies for this investigation were valuable in determining not only the demineralization periods but also the need for changing the demineralizing solutions of three experimental groups (75-day group, 90-day group and 120day group). Demineralizing solutions were replaced 60 days after immersion to avoid supersaturation, resulting from constant ionic exchanges occurring between the enamel and the fluid. Therefore, the specimens in the 75-day group, 90day group and 120-day group were kept immersed for more 15,30 and 60 days, respectively, after solution replacement.

\section{Imaging procedure}

Standardized radiographs of all specimens were acquired on the first and last day of solution treatment, considering all demineralization periods analyzed in this study, using the DenOptix ${ }^{\circledR}$ photostimulable phosphor plates (Dentsply International/Gendex ${ }^{\circledR}$ Dental X-ray Division, Des Plaines, IL, USA). The specimens were radiographed using a GE
$1000^{\circledR}$ X-ray unit (General Electric Co., Milwaukee, USA), operating at $70 \mathrm{kVp}, 10 \mathrm{~mA}, 2.5 \mathrm{~mm}$ total aluminum filtration and a $40 \mathrm{~cm}$ focus-receptor distance. The exposure time selected was $0.16 \mathrm{~s}$. An acrylic device was manufactured to hold the specimen, the X-ray beam indicator device and the image receptor in a reproducible relationship. With this support, a constant specimen-receptor distance of $1.5 \mathrm{~cm}$ was maintained, and the vertical and horizontal angulations of the X-ray tube were set at $0^{\circ}$ and $90^{\circ}$, respectively. A 2.5 $\mathrm{cm}$ thick acrylic plate was positioned in front of the specimens to simulate the soft tissues. The image receptors had an active area of $31 \times 41 \mathrm{~mm}$ and were scanned at a standard resolution of 300 dpi. Digital radiographs were then exported in TIFF (tagged image file format), 8 bits.

\section{Image assessment}

One experienced oral and maxillofacial radiologist examined the pairs of radiographs. In a calibration session, written and verbal instructions about digital radiographic image interpretation were provided. The observer was instructed to assess only proximal surfaces coronal to the cementoenamel junction and to compare the initial and the final radiographs. Any sign of demineralization was to be considered enamel subsurface demineralization, regardless of size, degree of penetration into enamel or treatment strategies.

Radiographs were imported into the EMAGO ${ }^{\circledR} /$ Advanced 3.43 software (Oral Diagnostic Systems, Amsterdam, The Netherlands) and presented in random order on a SVGA 17" monitor screen. Only one pair of radiographs was displayed at a time and all viewing was performed under uniform subdued lighting in a quiet, secluded room. The observer could use the software's brightness and contrast commands to manipulate image characteristics in order to better extract the signal of interest, as well as to apply the tool named zoom 1:1. This tool enables the observer to view the images at a $2 \mathrm{X}$ magnification. The analog brightness and contrast controls on the monitor were kept constant during the assessments.

The proximal surfaces in the final radiograph were scored using a five-point confidence rating scale: $1=$ enamel subsurface demineralization definitely absent; 2 = enamel subsurface demineralization probably absent; $3=$ unsure if enamel subsurface demineralization is present or absent; 4 = enamel subsurface demineralization probably present; and $5=$ enamel subsurface demineralization definitely present.

\section{Reproducibility}

To estimate the reproducibility, intra-observer agreement was analyzed using weighted kappa ( $\kappa)$ statistics. Following the calibration session, the observer was asked to examine 20 pairs of digital radiographs of the specimens used in the pilot studies twice. A two-week interval was allowed to elapse between the first and second examination. For intra-observer agreement, a $\kappa$ coefficient of 0.77 was obtained, indicating substantial reliability. 


\section{Validation}

Enamel test areas were submitted to Knoop crosssectional microhardness profiling. The crowns were sectioned from the roots and cut vertically through the center of the test areas. Both halves of each crown were embedded together in methylmethacrylate resin, so that the cut section would be exposed. This surface was serially polished and placed in a digital microhardness tester (FM Series $^{\circledR}$; Future-Tech Corp., Tokyo, Japan). Microhardness testing was carried out using the FM-ARS ${ }^{\circledR} 7000$ software (Sun-Tec Corp., Novi, MI, USA). Indentations were made with the long axis of a Knoop diamond indenter parallel to the outer enamel surface, under a $25 \mathrm{~g}$ load for $5 \mathrm{~s}$. Two rows spaced $200 \mu \mathrm{m}$ apart were established to allow enamel indentations at depths of 150,170, 190, 210, 230, 250, 270, $290,310,330,350,370,390$ and $410 \mu \mathrm{m}$. Thus, measurements were obtained at $20-\mu \mathrm{m}$ intervals up to $410 \mu \mathrm{m}$ through the enamel layer. Based on the width of each indentation, a Knoop hardness number (KHN) was automatically calculated by the FM-ARS ${ }^{\circledR} 7000$ software. One independent trained operator carried out all the microhardness measurements.

\section{Biochemical analyses}

The traditional colorimetric Fiske-Subbarow ${ }^{9}$ method was employed for determining inorganic $\mathrm{P}_{\mathrm{i}}$ concentration in demineralizing solutions. This method involves the transformation of phosphorus into phosphomolybdate, which is then reduced to a blue-colored product by the alpha-aminonaphthol-sulfonic acid. Color intensity was measured in a spectrophotometer (Beckman ${ }^{\circledR}$ DU-70) at a wavelength of $660 \mathrm{~nm}$, using standard curves of 1.5-24 $\mu \mathrm{g}$ $\mathrm{P}_{i} / \mathrm{mL}$. Ca concentration in demineralizing solutions was estimated using an atomic absorption spectrophotometer $\left(\operatorname{Varian}^{\circledR}\right.$, Spectra AA 50) at a wavelength of $422.7 \mathrm{~nm}$, previously calibrated with standard curves of 0.2-2 ppm calcium. $\mathrm{P}_{\mathrm{i}}$ and $\mathrm{Ca}$ concentrations in demineralizing solutions were measured twice. The first dosage was done 60 days after immersion, for all experimental groups; while the second was performed after solution replacement, for the 75-day, 90-day and 120-day groups.

\section{Statistical treatment}

Mean KHN values of each crown were averaged within the five studied groups. Cross-sectional microhardness mean values obtained for the control specimens from this randomized and uniform sample served as comparative parameters for the experimental groups. Data relative to the experimental groups were evaluated by two-way ANOVA $(p<0.05)$ associated with Tukey's test to analyze demineralization advance in the inner enamel layer. Comparisons were made by group and measuring depth. The analyses comprised measuring depths from $230 \mu \mathrm{m}$ to $410 \mu \mathrm{m}$, since data relative to the four initial depths were absent or incomplete due to severe enamel demineralization, which, in turn, impaired cross-sectional microhardness profiling.

One-way ANOVA, at a significance level of 5\%, was used to compare $\mathrm{P}_{i}$ and $\mathrm{Ca}$ mean concentrations among the experimental groups, before and after solution replacement.

The performance $\left(\mathrm{A}_{\mathrm{z}}\right)$ of the digital radiographs was assessed from the area under the ROC (receiver operating characteristic) curve. ROC curve was generated and $\mathrm{A}_{\mathrm{z}}$ was calculated using the STATA ${ }^{\circledR} 7.0$ package (StataCorp LP, College Station, USA).

During cross-sectional microhardness testing, one specimen in the 90-day group was damaged and had to be excluded from the material and statistical analyses.

\section{RESULTS}

\section{Analysis of variance for group and microhardness measuring depth}

Control group showed microhardness mean values ranging from 405 to $432 \mathrm{KHN}$. The 60-day group showed the highest microhardness mean values (179 to $379 \mathrm{KHN}$ ), whereas the lowest microhardness mean values (103 to 277 $\mathrm{KHN}$ ) were found for the 120-day group.

There were statistically significant differences between the 60-day group and the other experimental groups $(\mathrm{p}=$ 0.0000 ). Significant differences were also observed between the 75-day and 120-day groups $(\mathrm{p}=0.0002)$, and between the 90 -day and 120 -day groups $(p=0.0430)$. On the other hand, no significant difference was found between the 75day and 90-day groups.

With respect to measuring depth, the microhardness mean value at $230 \mu \mathrm{m}$ was observed to differ from all the others $(p<0.01)$, except that at $250 \mu \mathrm{m}(\mathrm{p}=0.3223)$, which showed no statistically significant difference only when compared to that obtained at $270 \mu \mathrm{m}(\mathrm{p}=0.3674)$. No significant difference was found between the microhardness mean values calculated at $270 \mu \mathrm{m}$ and $290 \mu \mathrm{m}(\mathrm{p}=0.2239)$. The microhardness mean value at $290 \mu \mathrm{m}$ differed from all the others $(\mathrm{p}<0.01)$, except that at $310 \mu \mathrm{m}(\mathrm{p}=0.0815)$, which showed no significant difference only when compared to that at $330 \mu \mathrm{m}(\mathrm{p}=0.9152)$. The value at $330 \mu \mathrm{m}$, in contrast, differed only from that at $410 \mu \mathrm{m}(\mathrm{p}=0.0357)$. Tukey test indicated no significant differences between the other measuring depth combinations. The highest microhardness mean values ( 277 to $378 \mathrm{KHN}$ ) were obtained at $410 \mu \mathrm{m}$ and the lowest (102 to $179 \mathrm{KHN}$ ) at $230 \mu \mathrm{m}$.

Figure 1 presents the cross-sectional microhardness profiles according to experimental group and measuring depth. Enamel microhardness decreased as the demineralization period increased. In addition, mineral loss was gradually reduced at the advanced measuring depths.

\section{Comparisons between $\mathrm{P}_{\mathrm{i}}$ and $\mathrm{Ca}$ concentrations}

Table 1 shows $\mathrm{P}_{\mathrm{i}}$ and $\mathrm{Ca}$ mean concentrations for each group. Statistical analyses demonstrated no significant differences among the experimental groups before solution replacement (for $\mathrm{P}_{\mathrm{i}}, \mathrm{p}=0.550$; and for $\mathrm{Ca}, \mathrm{p}=0.377$ ). Similarly, there were no statistically significant differences among the 75-day, 90-day and 120-day groups after solution 
replacement (for $\mathrm{P}_{\mathrm{i}}, \mathrm{p}=0.744$; and for $\mathrm{Ca}, \mathrm{p}=0.067$ ).

One-way ANOVA was then used to compare $\mathrm{P}_{\mathrm{i}}$ and $\mathrm{Ca}$ concentration mean values calculated for these three experimental groups ( 75 days, 90 days and 120 days) before and after solution replacement. Data from the three experimental groups were then summed for comparisons. Significant differences were found between the groups assessed concerning $\mathrm{P}_{\mathrm{i}}$ and $\mathrm{Ca}$ concentration mean values.
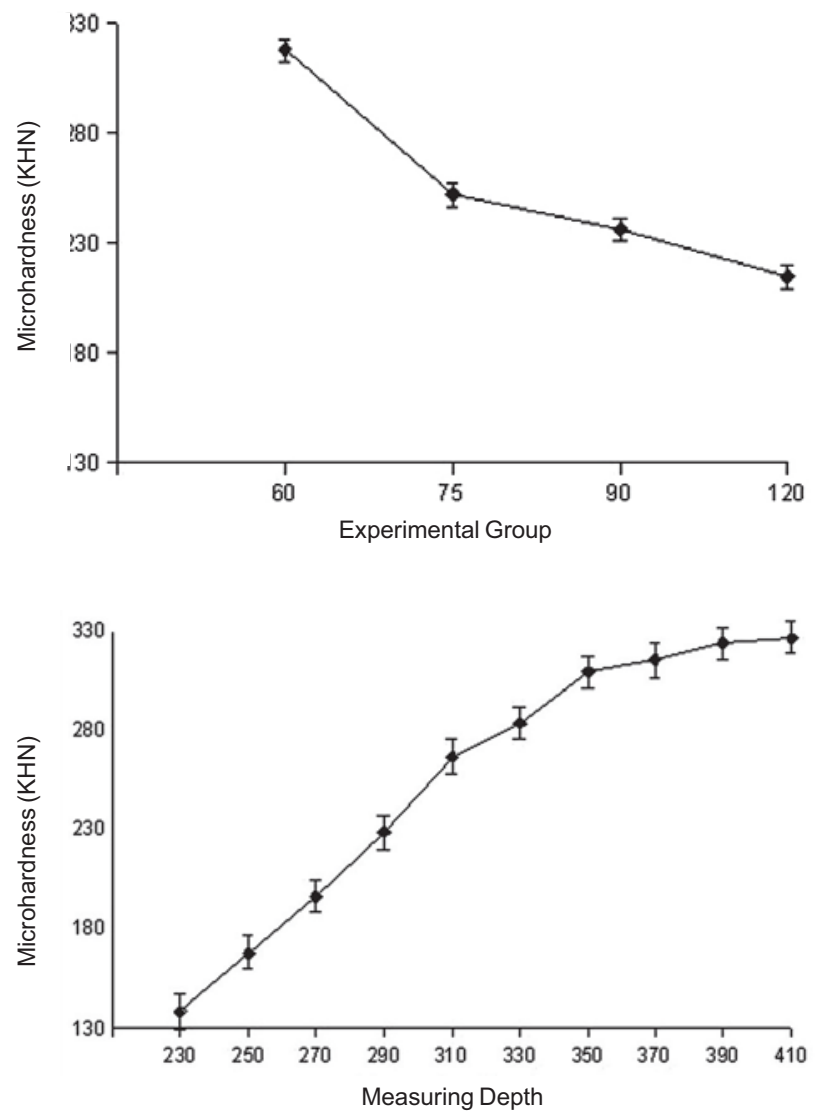

FIGURE 1- Cross-sectional microhardness profiles of the experimental specimens, by group (upper panel; 60 days, $n=10$; 75 days, $n=10$; 90 days, $n=9$; and 120 days, $n=$ 10 ) and measuring depth (lower panel; $n=39$ ). Bars indicate standard errors
$\mathrm{P}_{\mathrm{i}}$ and Ca mean concentrations were significantly lower after solution replacement $(\mathrm{p}=0.000)$. However, considering the values obtained before and after solution replacement for the 75-day, 90-day and 120-day groups, it may be inferred that the lowest total concentrations of $\mathrm{P}_{\mathrm{i}}$ and $\mathrm{Ca}(1.74 \mathrm{mM}$ and $2.63 \mathrm{mM}$, respectively) were found in the 60-day group, indicating the lowest rate of mineral loss.

\section{Performance of the diagnostic imaging method}

Radiographs acquired with the DenOptix ${ }^{\circledR}$ photostimulable phosphor plates demonstrated high performance, as the estimated $\mathrm{A}_{\mathrm{z}}$ value was 0.89 (95\% confidence interval of 0.82 - 0.96). Figure 2 shows radiographic images of experimental specimens prior to and after immersion in demineralizing solution. Although specimens in the four experimental groups exhibited radiographic images consistent with enamel caries lesions, subsurface demineralization was better visualized in radiographs concerning the 75-day, 90-day and 120-day groups.

\section{DISCUSSION}

Subsurface demineralization results from interaction between two components: dental enamel and external environment. The main factors known to control the stability of human dental enamel apatite are the $\mathrm{pH}$ and the free active calcium, phosphate and fluoride concentrations in solution ${ }^{2}$. Boyle, et al..$^{5}$ (1998) and Larsen and Bruun ${ }^{14}$ (2001) reported that subsurface caries lesion formation depends on hyposaturation of the aqueous phase of the system, regarding hydroxyapatite, and is related to the fluoride content of the substrate enamel at the demineralization site. Enamel solubility increases when $\mathrm{pH}$ remains around 5.0. Calcium and phosphate free concentrations also increase. However, it is not sufficient to counterbalance the dissolution process. As subsurface hydroxyapatite dissolves, fluorapatite is formed on the enamel surface as a result of fluoride adsorption. The rate of dissolution is proportional to the thermodynamic driving force during the

TABLE 1- Phosphorus $\left(P_{i}\right)$ and calcium (Ca) mean concentrations before and after demineralizing solution replacement

\begin{tabular}{llllll}
\hline Group & $\boldsymbol{n}$ & $\begin{array}{c}\mathbf{P}_{\mathbf{i}} \\
\mathbf{( 0 . 7 7} \mathbf{~ m M})^{*}\end{array}$ & $\begin{array}{l}\text { Standard } \\
\text { Error }\end{array}$ & $\begin{array}{c}\text { Ca } \\
(\mathbf{1 . 1 2} \mathbf{~ m M})^{*}\end{array}$ & $\begin{array}{l}\text { Standard } \\
\text { Error }\end{array}$ \\
\hline 60 days & 10 & $1.74 \mathrm{mM}$ & 0.21 & $2.63 \mathrm{mM}$ & 0.31 \\
75 days, before & 10 & $1.67 \mathrm{mM}$ & 0.38 & $2.46 \mathrm{mM}$ & 0.66 \\
75 days, after & 10 & $1.22 \mathrm{mM}$ & 0.15 & $1.71 \mathrm{mM}$ & 0.28 \\
90 days, before & 9 & $1.53 \mathrm{mM}$ & 0.46 & $2.30 \mathrm{mM}$ & 0.89 \\
90 days, after & 9 & $1.18 \mathrm{mM}$ & 0.15 & $1.91 \mathrm{mM}$ & 0.25 \\
120 days, before & 10 & $1.60 \mathrm{mM}$ & 0.18 & $2.17 \mathrm{mM}$ & 0.48 \\
120 days, after & 10 & $1.24 \mathrm{mM}$ & 0.16 & $1.62 \mathrm{mM}$ & 0.26 \\
\hline
\end{tabular}

\footnotetext{
* Reference values
} 
ionic exchanges ${ }^{2}$.

In the present study, Knoop cross-sectional microhardness profiling constituted the validation method for the experimentally induced enamel demineralization. Although histological examination of caries lesions is an ideally reproducible validation method and considered scientifically acceptable for in vitro research ${ }^{10,11,20}$, other techniques, such as cross-sectional microhardness testing and biochemical analyses have been used to measure the alterations in dental hard tissues ${ }^{3,4,8,21}$.

Cross-sectional microhardness testing provides information on the physical property of enamel hardness and depth of demineralization. Unlike other histological methods, this approach enables to estimate small alterations in mineral content at predetermined depths. This validation method was considered appropriate as microhardness mean values obtained for the control group ranged from 405 to $432 \mathrm{KHN}$. Such variation might have resulted from small amounts of organic substance at sites of similar mineral content ${ }^{13}$.

Statistical analysis concerning microhardness data demonstrated significant differences among the experimental groups, except for the 75-day and 90-day groups. It should be taken into account, however, that the specimens of the 90-day group remained immersed in demineralizing solution for only 15 more days in relation to those of the 75-day group.

Microhardness mean values for $410 \mu \mathrm{m}$, showing the highest KHN, were lower in the experimental groups when compared to the control. For the experimental groups, no statistically significant differences were found between the depth level of $350 \mu \mathrm{m}$ and the other last depths tested.
Therefore, it can be suggested that the highest demineralization rates were registered in the inner enamel layer comprising $330 \mu \mathrm{m}$ inward from the anatomical surface.

Interestingly, microscopic observation of enamel test areas of the 60-day group specimens gives rise to a supposition that the enamel lying $410 \mu \mathrm{m}$ inward from the surface would be at least $100 \mu \mathrm{m}$ far from a cavitation due to disruption of the outer layer. Nevertheless, the microhardness mean value calculated at $410 \mu \mathrm{m}$ for the 60-day group was lower than that obtained for the control.

Determination of $\mathrm{P}_{\mathrm{i}}$ and $\mathrm{Ca}$ in the demineralizing solutions was considered an indirect method for monitoring mineral loss. In this in vitro model, as all the specimens in the 60day, 75-day, 90-day and 120-day groups were kept individually immersed in demineralizing solution for 60 days before replacement, the null hypothesis stated there were differences among the four experimental groups. Rejection of null hypothesis caused no surprise, as the demineralizing solution prepared was the same for all the experimental groups and the teeth were still sound on the first day of immersion.

After the initial 60-day period, the demineralizing solutions of the 75-day, 90-day and 120-day groups were replaced by the same solution prepared in the beginning of the experiment to avoid supersaturation. If supersaturation occurs, demineralization does not progress toward the dentin-enamel junction as the kinetics of ionic exchange becomes too slow. At this stage, dental enamel of the specimens in the groups cited above had already undergone some demineralization. Thus, immersion in an undersaturated solution was thought to determine the progression of enamel demineralization. In fact, enamel demineralization was

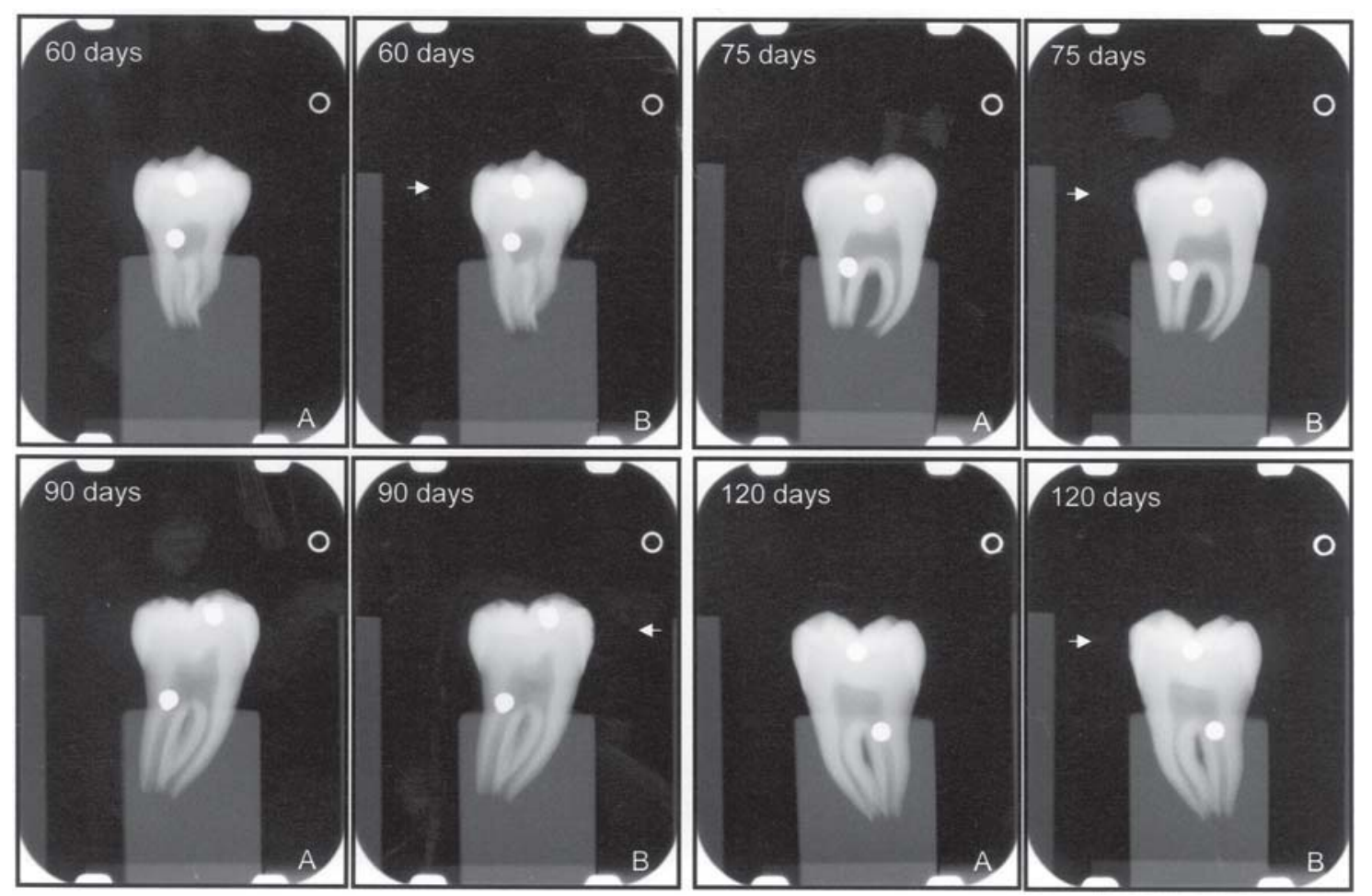

FIGURE 2- Radiographic images of experimental specimens, before (A) and after (B) the demineralization periods. Arrow indicates the proximal surface presenting an artificial enamel subsurface demineralization 
observed to advance, though less intense than expected. No significant difference was found among the 75-day, 90day and 120-day groups. However, ionic concentrations for the 60-day group were significantly different from those obtained for the other three experimental groups, corresponding to the lowest total $\mathrm{P}_{\mathrm{i}}$ and $\mathrm{Ca}$ loss. These findings do not support the initial supposition that mineral loss would be linear and directly proportional to the immersion period. Otherwise, it appeared to be a rate-limiting process.

The ionic exchanges were believed to slow down after solution replacement for two reasons: (1) the fluoride in demineralizing solution at a $\mathrm{pH}$ level higher than that considered critical for fluorapatite dissolution, even at a $0.03 \mathrm{ppm}$ concentration, was incorporated into the enamel surface, making it more rigid, reducing the enamel pores and consequently decreasing the ionic transport; (2) a decrease in the ion diffusion gradient through the demineralization zone might also have contributed to such an event. Presumably, $\mathrm{pH}$ should be set at levels lower than 4.5 so that demineralization would reach the dentin-enamel junction. Hence, fluorapatite would be removed from de surface enamel and demineralization would progress. It should be emphasized that, in this experiment, $\mathrm{P}_{\mathrm{i}}$ and $\mathrm{Ca}$ lost remained in the plastic vials in which the specimens were stored. In the mouth, however, these minerals are kinetically transported by the action of masticatory muscles and the dynamics of salivary flow.

Although the specimens were individually evaluated, repetition means were used for the analyses of variance with the aim of providing overall data from the studied groups. However, because of the anatomy and the chemical and ultra-structural composition of the hydroxyapatite crystals, teeth can behave differently to the acid challenge from the demineralizing solution ${ }^{1,6,17}$. According to Dowker, et al. ${ }^{6}$ (2003) structure, porosity and solubility of dental enamel are linked during the demineralization process. The decrease in apatite solubility with fluoride substitution, as well as the opposite condition with carbonate and magnesium substitution, has been related to the dissolution of dental enamel ${ }^{6,17}$.

It may be inferred that there was a correspondence between cross-sectional microhardness data and $\mathrm{P}_{\mathrm{i}}$ and $\mathrm{Ca}$ concentrations. The highest microhardness values and the lowest ionic concentrations relative to the total mineral loss were obtained for the 60-day group. The 75-day and 90-day groups demonstrated a similar behavior. Apparent dissimilarity was found in microhardness data from the 120 day group, corroborating the greater suitability of the validation method.

From a clinical point of view, the diagnostic imaging methods gain striking relevance in the detection of subtle proximal enamel demineralization caused by caries progression. The smaller the depicted signal, the greater is the validity of radiographic images. In general, radiographic images of extensive lesions and mechanically created defects have relatively sharp borders and high contrast, since these kinds of cavities contain air ${ }^{12}$. On the other hand, natural caries lesions have gradual boundaries and often contain varying amounts of calcified salts. Because the initial process of caries lesion formation in dental enamel involves purely biochemical changes that may be well-reproduced in vitro, subsurface demineralization was induced to simulate natural "white spot" caries lesions. The $A_{z}$ value (0.89) calculated for digital radiographs was observed to be high, indicating that the diagnostic imaging method employed was sufficiently appropriate for detecting enamel subsurface alterations, even after a demineralization period as short as 60 days. Hintze and Wenzel ${ }^{11}$ (2002) mentioned that values of $\mathrm{A}_{\mathrm{z}}$ exceeding 0.90 for proximal enamel and dentinal caries lesions are very rarely seen for radiographic modalities validated against histology.

Nevertheless, based on image assessments and in accordance with other studies $7,12,15$, it may be sustained that, in spite of the great diagnostic usefulness, the extent of subsurface demineralization is frequently underestimated from radiography. Due to factors related to the exposure geometry, such as X-ray beam angulations and lesion morphology, demineralization showing distinct features concerning structure, activity and extension may have identical radiographic aspects ${ }^{7,20}$. Therefore, in patients known to be more prone to dental caries disease, the combination of different diagnostic methods associated with visual inspection might increase early detection of enamel subsurface demineralization, providing them with a noninvasive treatment.

\section{CONCLUSION}

This in vitro model of inducing enamel subsurface demineralization was considered suitable for studies focusing on the evaluation of imaging methods for the diagnosis of proximal caries lesions in human permanent teeth. Digital radiographs exhibited enamel subsurface mineral loss; however, the produced images of the artificial lesions were better visualized as the demineralization period increased.

\section{REFERENCES}

1- Anderson P, Elliott JC. Rates of mineral loss in human enamel during in vitro demineralization perpendicular and parallel to the natural surface. Caries Res. 2000;34:33-40.

2- Anderson P, Elliott JC. Subsurface demineralization in dental enamel and other permeable solids during acid dissolution. J Dent Res. 1992;71:1473-81.

3- Arends J, ten Bosch JJ. Demineralization and remineralization evaluation techniques. J Dent Res. 1992;71(sp issue):924-8.

4- Argenta RMO, Tabchoury CPM, Cury JA. A modified pH-cycling model to evaluate fluoride effect on enamel demineralization. Pesqui Odontol Bras. 2003;17:241-6.

5- Boyle EL, Higham SM, Edgar WM. The production of subsurface artificial caries lesions on third molar teeth. Caries Res. 1998;32:1548 . 
6- Dowker SEP, Elliott JC, Davis GR, Wassif HS. Longitudinal study of the three-dimensional development of subsurface enamel lesions during in vitro demineralisation. Caries Res. 2003;37:237-45.

7- Espelid I, Tveit AB. Radiographic diagnosis of mineral loss in approximal enamel. Caries Res. 1984;18:141-8.

8- Featherstone JDB, ten Cate JM, Shariati M, Arends J. Comparison of artificial caries-like lesions by quantitative microradiography and microhardness profiles. Caries Res. 1983;17:385-91.

9- Fiske CM, Subbarow Y. The colorimetric determination of phosphorus. J Biol Chem. 1925;66:375-400.

10- Hintze H, Wenzel A. Diagnostic outcome of methods frequently used for caries validation. A comparison of clinical examination, radiography and histology following hemisectioning and serial tooth sectioning. Caries Res. 2003;37:115-24.

11- Hintze $H$, Wenzel A. Influence of the validation method on diagnostic accuracy for caries. A comparison of six digital and two conventional radiographic systems. Dentomaxillofac Radiol. $2002 ; 31: 44-9$

12- Kang BC, Goldsmith LJ, Farman AG. Observer differentiation of mechanical defects versus natural dental caries cavitations on monitordisplayed images with imaging plate readout. Oral Surg Oral Med Oral Pathol Oral Radiol Endod. 1998;86:595-600.

13 - Kodaka T, Debari K, Yamada M, Kuroiwa M. Correlation between microhardness and mineral content in sound human enamel (short communication). Caries Res. 1992;26:139-41.

14- Larsen MJ, Bruun C. A química da cárie dentária e o flúor mecanismos de ação. In: Thylstrup A, Fejerskov O. Cariologia clínica. 3.ed. São Paulo: Santos; 2001. p. 231-58.

15- Lenhard M, Mayer T, Pioch T, Eickholz P. A method to monitor dental demineralisation in vitro. Caries Res. 1996;30:326-33.

16- Pine CM, ten Bosch JJ. Dynamics of and diagnostic methods for detecting small carious lesions. Caries Res. 1996;30:381-8.

17- Shellis RP. Relationship between human enamel structure and the formation of caries-like lesions in vitro. Archs Oral Biol. 1984;29:97581

18 - ten Cate JM. Remineralization of caries lesions extending into dentin. J Dent Res. 2001;80:1407-11.

19- Thylstrup A, Fejerskov O. Características clínicas e patológicas da cárie dentária. In: Thylstrup A, Fejerskov O. Cariologia clínica. 3.ed. São Paulo: Santos; 2001. p. 111-58.

20 - Wenzel A, Hintze H. The choice of gold standard for evaluating tests for caries diagnosis. Dentomaxillofac Radiol. 1999;28:132-6.

21- White DJ, Faller RV, Bowman WD. Demineralization and remineralization evaluation techniques - added considerations. J Dent Res. 1992;71(Spec Iss):929-33. 